\title{
Caracterização de uma Nova Estirpe do Tomato mosaic virus isolada de Tomateiro no Estado de São Paulo
}

\author{
Silvia R. Moreira ${ }^{1}$, Marcelo Eiras ${ }^{1}$, Alexandre L.R. Chaves ${ }^{1}$, Silvia R. Galleti ${ }^{2}$ \& Addolorata Colariccio $^{1}$ \\ ${ }^{1}$ Centro de Pesquisa e Desenvolvimento de Sanidade Vegetal, ${ }^{2}$ Unidade Laboratorial de Referência em Microscopia \\ Eletrônica, Instituto Biológico, Av. Conselheiro Rodrigues Alves, 1252, CEP 04014-002, São Paulo, SP, e-mail: \\ colariccio@biologico.sp.gov.br
}

(Aceito para publicação em 01/09/2003)

Autor para correspondência: Addolorata Colariccio

MOREIRA, S.R., EIRAS, M., CHAVES, A.L.R., GALLETI, S.R. \& COLARICCIO, A. Caracterização de uma nova estirpe do Tomato mosaic virus isolada de tomateiro no Estado de São Paulo. Fitopatologia Brasileira 28:602-607. 2003.

\section{RESUMO}

Um vírus isolado em Guaratinguetá, SP, de tomateiro (Lycoporsicon esculentum) 'Santa Clara' com sintomas característicos de virose, foi estudado por meio de plantas indicadoras e de hospedeiras diferenciais pertencentes a linhagens homozigotas de tomateiro, ensaios de estabilidade in vitro, purificação, contrastação negativa, testes sorológicos de ELISA-PTA e imunomicroscopia eletrônica, utilizando-se anti-soros contra diferentes vírus do gênero Tobamovirus. O isolado infetou plantas de espécies de amarantáceas, quenopodiáceas e solanáceas. Plantas de Chenopodium amaranticolor reagiram com sintomas locais e sistêmicos; Nicotiana sylvestris e $N$. rustica reagiram com lesões locais e a linhagem homozigota de tomateiro Tm-2 mostrouse imune ao vírus. Nas preparações purificadas de contrastação negativa, foram observadas partículas rígidas e alongadas com cerca de $300 \mathrm{~nm}$. $\mathrm{O}$ isolado foi identificado como um tobamovírus, com anti-soros contra o Tomato mosaic virus (ToMV) e Tobacco mosaic virus (TMV). As hospedeiras diferenciais indicaram se tratar de ToMV. Por meio de RTPCR, com oligonucleotídeos para o gene da capa protéica de espécies do gênero Tobamovirus do subgrupo 1, amplificaram-se fragmentos com $850 \mathrm{pb}$ que foram clonados e sequienciados. A similaridade de nucleotídeos e aminoácidos deduzidos variou entre 85 e $91 \%$ quando a sequiência do ToMV-SP foi comparada com outras sequências de ToMV, 75 e $83 \%$ quando comparada com as do TMV e 67 e $72 \%$ quando comparada com a do Odontoglossum ringspot virus (ORSV). As comparações com outras espécies de tobamovírus apresentaram valores de similaridade inferiores a $65 \%$. Confirmou-se a identidade dos vírus como sendo uma nova estirpe do ToMV.

Palavras-chave adicionais: Tobamovirus, hospedeiras diferenciais, sorologia, seqüenciamento.

\section{ABSTRACT}

Characterization of a new Tomato mosaic virus strain isolated from tomato in the State of São Paulo, Brazil

Tomato (Lycoporsicon esculentum) plants 'Santa Clara' from the city of Guaratinguetá in the State of São Paulo, Brazil, show typical virus symptoms in this study. The evaluation was carried out by using indicator plants and differential tomato genotypes with resistance factors of Tm-1, Tm-2 and Tm- $2^{2}$; virus stability in sap; purification; and negative staining, PTA-ELISA and ISEM. The isolates infected plants from several species of Amaranthaceae, Chenopodiaceae and Solanaceae. Chenopodium amaranticolor plants reacted with local and systemic symptoms; Nicotiana sylvestris and $N$. rustica reacted with local lesions and the tomato Tm-2 showed immunity. Rod-shaped particles about $300 \mathrm{~nm}$ were observed in negatively stained preparations. The isolate reacted against Tomato mosaic virus (ToMV) and Tobacco mosaic virus (TMV) antisera. Based on host plants, the isolate was identified as tToMV and by the tomato genotype response, but it could be not identified as the 0 or I ToMV strain. In order to confirm the identity of the virus, RT-PCR was performed with specific primers for the tobamovirus coat protein gene and the amplified DNA was cloned and sequenced. The nucleotides and deduced aminoacids showed 85 and $91 \%$ similarity when compared to ToMV sequences, 75 and $83 \%$ similarity with those of TMV, and 67 and $72 \%$, with Odontoglossun ringspot virus (ORSV). For other tobamovirus species, the similarity values were lower than $65 \%$. The virus was confirmed as a new ToMV strain.

\section{INTRODUÇÃO}

Dentre os fitovírus já relatados causando perdas significativas na cultura do tomateiro (Lycopericon esculentum Mill.), destacam-se os pertencentes aos gêneros Cucumovirus, Luteovirus, Potexvirus, Potyvirus, Tobamovirus e Tospovirus (Blancard, 1996; Faria et al., 2000; Colariccio et al., 2001). Do gênero Tobamovirus, família Tombusviridae, fazem parte os vírus com forma de bastonetes rígidos com $300 \mathrm{~nm}$ de comprimento, simetria helicoidal, constituídos de RNA de fita simples com cerca de 6.400 nucleotídeos e quatro fases abertas de leitura (ORF). Os vírus deste gênero apresentam distribuição mundial em regiões de clima temperado e tropical (Van Regenmortel et al., 2000), são transmitidos por contato mecânico, decorrente das práticas culturais, podendo permanecer em resíduos vegetais, no solo e na água por longos períodos, não havendo, até o momento, vetores conhecidos. Também podem ser transmitidos por sementes, infestando a superfície do tegumento, mucilagem externa, testa e endosperma, não sendo transmitidos por pólen. Possuem ampla 
gama de hospedeiras, tendo sido relatados em nove famílias botânicas (Brunt et al., 1996).

Dezessete espécies constituem o gênero Tobamovirus (Van Regenmortel et al., 2000; Antignus et al., 2001). Atualmente, o gênero Tobamovirus está dividido em três subgrupos, sendo o ToMV pertencente ao subgrupo 1, juntamente com o TMV, Tobacco mild green mosaic virus (TMGMV), Odontoglossum ringspot virus (ORSV) e Pepper mild mottle virus (PMMoV). Esta classificação é feita em função de parâmetros como origem de montagem da partícula, número de nucleotídeos presentes entre duas diferentes ORFs, análise filogenética e hospedeiras, sendo o subgrupo 1 denominado subgrupo das solanáceas, o 2 das crucíferas e o 3 das cucurbitáceas, tendo como membro-tipo o TMV, o Turnipe vein-clearing virus (TVCV) e o Cucumber green mottle mosaic virus (CGMMV), respectivamente (Lartey et al., 1996).

No Brasil, há somente relatos da ocorrência de espécies do gênero Tobamovirus pertencentes ao subgrupo 1: o TMV infetando tomateiro, Nicotiana tabacum L., Petunia sp. e Zinnia sp.; o ToMV infetando tomateiro; o ORSV em Cymbidium sp.; e mais recentemente o PMMoV infetando pimenta (Capsicum baccatum L.) e pimentão (C. annuum L.) (Caner et al., 1990; Bastos et al., 1999; Alexandre et al., 2000; Maritan \& Gaspar, 2001; Kobori et al., 2001; Moreira et al., 2001; Eiras et al., 2003). As primeiras descrições do ToMV, no Brasil, foram feitas por Costa et al. (1971), Fernandes et al. (1983) e Caner et al. (1990), tendo sido feita, neste último relato, a descrição de uma estirpe severa causando quebra da produção em tomateiros na Região de Conchal, SP.

O presente trabalho teve como finalidade a caracterização de um isolado de tobamovírus em tomateiros 'Santa Clara', por meio de análises ao microscópio eletrônico de transmissão, da caracterização biológica da espécie e estirpe utilizando hospedeiras diferenciais, purificação, produção de anti-soro, testes sorológicos e moleculares.

\section{MATERIALEMÉTODOS}

\section{Fonte e manutenção do vírus}

Tomateiros 'Santa Clara' com sintomas sistêmicos semelhantes à infecção causada pelo ToMV, tais como afilamento, distorção e bolhas nos folíolos, foram coletados no município de Guaratinguetá, Vale do Paraíba-SP.

Visando a manutenção da fonte de vírus, extrato vegetal obtido desses tomateiros foi empregado na inoculação mecânica em plantas de $N$. tabacum 'White Burley' e tomateiro 'Santa Clara', as quais foram mantidas em casa de vegetação. Além disso, tanto o material original quanto as plantas inoculadas foram armazenadas em cloreto de cálcio a $-20^{\circ} \mathrm{C}$.

\section{Gama de Hospedeiras}

O extrato vegetal empregado nos ensaios de inoculação mecânica para a determinação da gama de hospedeiras foi preparado pela homogenização de folhas de N. tabacum 'White Burley' infetadas, em presença de solução de sulfito de sódio 0,5\%, pH 6,0 na proporção de 1:5 (g:ml), adicionando- se carborundum (400 mesh) como abrasivo. Após a inoculação, as plantas foram mantidas em casa de vegetação para a observação dos sintomas. Foram inoculadas mecanicamente plantas de 27 espécies vegetais e variedades pertencentes a nove famílias botânicas: Gomphrena globosa L. (Amaranthaceae), Chenopodium quinoa Willd., C. murale L. (Chenopodiaceae), Sonchus oleraceos L. (Compositae), Cucumis sativus L., Citrullus lunatus Schrad. (Cucurbitaceae), Glicine max (L.) Merrill., Vigna unguiculata L. (Fabaceae), Hybiscus esculentus L. (Malvaceae), Passiflora edulis Sims. (Passifloraceae), Capsicum annuum L. 'Reinger', C. bacatum L. 'Dedo de Moça', Datura metel L., D. stramonium L., L. esculentum 'Gaúcho', 'Jumbo' e 'Santa Clara', N. clevelandii Gray., N. debneyi Domin., N. glutinosa L., N. tabacum 'Samsun', 'Samsun NN', 'TNN', 'Turkish', 'Xanthii' e 'White Burley' (Solanaceae), Plantago tomentosa Lam. (Plantaginaceae) e Tetragonia expansa L. (Tetragoniaceae). Na ausência de sintomas, foram feitos testes de recuperação do vírus por meio da inoculação mecânica em plantas de N. tabacum 'White Burley', a fim de se verificar a ocorrência de latência.

Plantas de C. amaranticolor, N. sylvestris Speg \& Comes., N. rustica L., petunia (Petunia hybrida Vilm.), diferenciais para TMV e ToMV, e linhagens de tomateiro 'Tm1', homozigoto resistente ao ToMV, 'Tm-2' e 'Tm-2 2 ' homozigotos resistentes ao TMV 1 e 2 e 'Santa Clara' suscetível ao ToMV, foram inoculadas com o isolado e mantidas em casa de vegetação para identificação do vírus por meio da manifestação de sintomas.

\section{Purificação do vírus}

Folhas infetadas de N. tabacum 'White Burley' foram utilizadas no processo de purificação. Empregou-se o método descrito por Caner et al. (1990), com modificações pela adição de $2,5 \%$ de polietilenoglicol (PEG) e $0,1 \mathrm{M}$ de $\mathrm{NaCl}$ ao volume final do sobrenadante, sob agitação em banho de gelo nas fases de clarificação e precipitação. A preparação semipurificada do vírus foi submetida a gradiente de densidade linear de sacarose (10-40\%), o qual foi ultracentrifugado a $80.000 \mathrm{~g}$ por $2,5 \mathrm{~h}$. A banda resultante foi recolhida e submetida a uma nova ultracentrifugação nas mesmas condições anteriores. Ao final do processo, foi realizada leitura de absorbância em espectrofotômetro (Shimadzu UV-160A) nos comprimentos de onda entre 200 e $300 \mathrm{~nm}$. A concentração do vírus na preparação purificada foi estimada com base no valor 3 do coeficiente de extinção dos tobamovírus. A porcentagem de ácido ribonucléico (RNA) presente nas partículas virais foi estimada pela leitura de absorbância $\left(\mathrm{A}_{260} / \mathrm{A}_{280}\right)$, segundo a fórmula de Gibbs \& Harrison (1976).

\section{Produção de anti-soro}

Três injeções da preparação purificada $(6 \mathrm{mg} / \mathrm{ml})$ do isolado ToMV-SP, sendo a primeira emulsionada em adjuvante completo de Freund (1:1) e as demais em adjuvante incompleto, foram aplicadas no linfonodo de um coelho da raça Nova Zelândia a cada 15 dias. Uma semana após a última injeção, promoveram-se a sangria e a separação do anti-soro, que foi 


\section{S.R. Moreira et al.}

titulado por meio de ELISA-PTA, aliquotado e mantido a $-20^{\circ} \mathrm{C}$.

\section{Testes sorológicos}

Utilizou-se o ELISA-PTA para a identificação sorológica do vírus, empregando-se anti-soros contra a capa protéica de quatro espécies de tobamovírus: ToMV-SP, TMV-Pet isolado de petúnia, Frangipani mosaic virus (FrMV) e Ribgrass mosaic virus (RGMV). Além disso, realizou-se ELISA-PTA confrontando o TMV e o ToMV com os respectivos anti-soros nas diluições 1:4.000 e 1:13.000, para verificar o relacionamento sorológico e a especificidade dos anti-soros produzidos contra o ToMV-SP e o TMV-Pet. Após as reações imuno-enzimáticas, foram realizadas leituras de absorbância $\left(\mathrm{A}_{405 \mathrm{~nm}}\right)$ em leitor BioRad modelo 3550.

Para os testes de imunomicroscopia eletrônica, empregaram-se AS-ToMV-SP e AS-TMV-Pet utilizados no ELISA. Para visualizar partículas virais decoradas pelos antisoros ao microscópio eletrônico de transmissão Phillips EM 208 empregou-se extrato foliar de N. tabacum "White Burley" experimentalmente infetadas com ToMV-SP e TMV-Pet.

\section{Extração de RNAs totais}

Para a extração de RNAs totais, $1 \mathrm{~g}$ de amostras foliares de tomateiro infetado pelo isolado ToMV-SP foi submetido ao procedimento descrito por Eiras et al. (2001). Amostras de RNAs totais de folhas de tomateiro sadias também foram extraídas para servirem como controles negativos.

\section{RT-PCR}

A RT-PCR seguiu de acordo com Alexandre et al. (2000), partindo-se de $1 \mu \mathrm{g}$ de RNAs totais extraídos e utilizando-se oligonucleotídeos iniciadores que flanqueiam a ORF da capa protéica (Figura 1A), desenhados por meio do alinhamento de diferentes espécies de Tobamovirus já seqüenciadas. Para a PCR, foi utilizado o termociclador Programmable Thermal Controller - PTC100 (MJ Research), e os reagentes do kit Taq DNA Polymerase recombinant (Gibco BRL), seguindo as recomendações do fabricante. As condições para a PCR constaram de uma desnaturação inicial a $94{ }^{\circ} \mathrm{C}$ por $5 \mathrm{~min}$, seguida de 35 ciclos a $94^{\circ} \mathrm{C}$ por $45 \mathrm{~s}, 55^{\circ} \mathrm{C}$ por 1 min e $72{ }^{\circ} \mathrm{C}$ por $1,5 \mathrm{~min}$, com uma extensão final de $10 \mathrm{~min}$ a $72^{\circ} \mathrm{C}$. Os fragmentos de DNA amplificados foram visualizados em gel de agarose 1,0 $\%(\mathrm{p} / \mathrm{v})$ corado com brometo de etídeo sob luz ultravioleta.

\section{Clonagem}

Os produtos amplificados via RT-PCR foram eluídos do gel de agarose, utilizando-se o kit "Concert Rapid Gel Extraction System” (Life Technologies). Em seguida, foram ligados em pGEM-T vector (Promega) e utilizados para a transformação de células competentes de Escherichia coli (DH5- $\alpha$ ). Todos esses procedimentos seguiram as recomendações dos respectivos fabricantes e indicações contidas em Sambrook et al. (1989).

\section{Seqüienciamento}

Os produtos amplificados via RT-PCR foram seqüenciados pela técnica de reação de terminação em cadeia, utilizando-se o seqüenciador automático ABI 377 e o "kit ABI PRISM BigDye Terminator Cycle Sequencing Ready Reaction Kit - Ampli Taq DNA Polymerase" (Perkin Elmer) seguindo as recomendações do fabricante. $\mathrm{O}$ alinhamento das seqüências obtidas nos dois sentidos foi feito com o auxílio do programa Sequencer 3.1 (Gene Codes Corporation) e as comparações, com as seqüências existentes no GenBank, foram feitas através do programa "Basic Local Alignment Search Tool" (BLAST) do "National Center for Biotechnology Information" (NCBI), disponível no endereço http://www.ncbi.nlm.nih.gov.

As sequiências foram alinhadas (Clustal X) com outras sequiências de isolados de ToMV, TMV e ORSV depositadas no GenBank, sendo obtido um dendrograma (TreeView 1.5) das seqüências de nucleotídeos. A seqüência de nucleotídeos obtida neste trabalho foi depositada no GenBank com o código de acesso AF411922.

\section{RESULTADOS E DISCUSSÃO}

Os resultados obtidos revelaram uma gama de hospedeiras semelhante àquela descrita na literatura para tobamovírus. Entretanto, algumas hospedeiras empregadas como diferenciais reagiram com sintomas diferentes dos citados (Brunt et al., 1996). Chenopodium amaranticolor desenvolveu sintomas sistêmicos semelhantes aos causados pelo RGMV, porém $P$. tomentosa reagiu com lesões locais necróticas não descritas para este último, enquanto $N$. rustica, N. sylvestris e $P$. hybrida, reagiram com lesões locais características para o

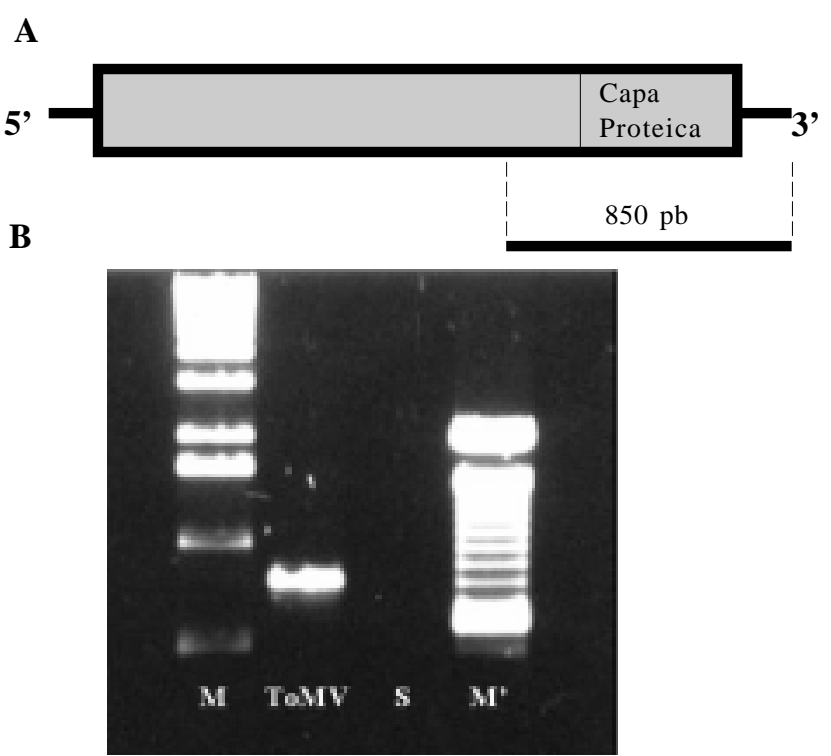

FIG. 1 - A) desenho esquemático das regiões de anelamento dos oligonucleotídeos iniciadores e o produto esperado com 850 pares de bases (pb) da amplificação via RT-PCR do Tomato mosaic virus (ToMV); B) análise em gel de agarose $1 \%$ corado com brometo de etídeo do isolado ToMV-SP, amplificado via RT-PCR, a partir de RNAs totais extraídos de folíolos de tomateiro infetados. ToMV representa os fragmentos de DNA com $850 \mathrm{pb}$; S representa RT-PCR de RNAs totais extraídos de folíolos de tomateiro sadios; M - 1kb DNA ladder; M' - 100 pb DNA ladder (Gibco-BRL). 
ToMV, conforme descrito por Hollings \& Huttinga (1976). Capsicum baccatum 'Dedo de Moça' hospedeira sistêmica do PMMoV (Brunt et al., 1996), reagiu com lesões locais necróticas (Tabela 1). Gomphrena globosa reagiu com sintomas necróticos locais e sistêmicos; T. expansa e P. edulis reagiram com lesões locais cloróticas e necróticas, respectivamente. As demais espécies reagiram com sintomas típicos aos induzidos por tobamovírus, exceto as espécies pertencentes às famílias Compositae, Cucurbitaceae, Fabaceae e Malvaceae que não manifestaram sintomas.

Este isolado manifestou, ainda, sintomas típicos de mosaico, bolhas, distorção, afilamento e necrose foliar nas linhagens de tomateiro homozigotas com genes de resistência Tm- 1, Tm- $2^{2}$ e na cultivar 'Santa Clara'. Tomateiros da linhagem Tm- $2^{2}$ também apresentaram subdesenvolvimento e superbrotamento, enquanto os tomateiros da linhagem Tm-2 não manifestaram sintomas (Tabela 1). Os testes de recuperação em N. tabacum 'White Burley' foram negativos para as plantas assintomáticas. Os resultados possibilitaram a identificação, neste material, de uma estirpe intermediária do ToMV, entre as estirpes 0 e 1, que se designou de ToMV-SP. A ocorrência de estirpes intermediárias já havia sido relatada nos Estados Unidos por Fletcher \& Mcneill (1971), que observaram a predominância da estirpe 1 e a ocorrência de estirpes intermediárias às estirpes 0 e 1 em 14\% dos isolados de ToMV por eles estudados. No Brasil, levantamentos realizados por Bastos et al.(1999), em quatro municípios paulistas, revelaram a predominância da estirpe 1 , a ocorrência da estirpe 0 e nenhum relato de estirpes intermediárias. Porém, neste trabalho e em avaliações posteriores realizadas com tomateiros provenientes da Região do Vale do Paraíba e Indaiatuba, SP, portanto em outras regiões do estado, verificou-se novamente, a ocorrência da estirpe intermediária do ToMV (Moreira et al., 2000).

TABELA 1 - Resultado da inoculação com o isolado do Tomato mosaic virus (ToMV), proveniente de Guaratinguetá (ToMV-SP) em plantas hospedeiras diferenciais utilizadas na identificação das espécies do gênero Tobamovirus e linhagens homozigotas de tomateiro (Lycopersicon esculentum) empregadas para a identificação das estirpes do vírus

\begin{tabular}{|c|c|c|c|}
\hline Família & Espécie & $\begin{array}{l}\text { Sintoma } \\
\text { Local* }\end{array}$ & $\begin{array}{l}\text { Sintoma } \\
\text { Sistêmico** }\end{array}$ \\
\hline Chenopodiaceae & Chenopodium amaranticolor & $\mathrm{PC}, \mathrm{PN}$ & $\mathrm{PC}, \mathrm{PN}$ \\
\hline Plantaginaceae & Plantago tomentosa & $\mathrm{PN}$ & - \\
\hline \multirow[t]{9}{*}{ Solanaceae } & Capsicum baccatum & $\mathrm{LN}$ & - \\
\hline & Nicotiana rustica & $\mathrm{LN}$ & - \\
\hline & N. sylvestris & LN & - \\
\hline & Petunia hybrida & LN & - \\
\hline & Lycopersicon esculentum & & \\
\hline & $\mathrm{Tm}-1$ & $\mathrm{PC}, \mathrm{PN}$ & $\mathrm{PC}, \mathrm{PN}$ \\
\hline & $\mathrm{Tm}-2$ & - & - \\
\hline & $\operatorname{Tm} 2$ & $\begin{array}{l}\text { AF, B, DF, } \\
\text { LN }\end{array}$ & $\begin{array}{l}\text { AF, B, DF, } \\
\text { LN, N, M, S }\end{array}$ \\
\hline & Santa Clara & $\begin{array}{l}\text { AF, B, DF, } \\
\text { LN }\end{array}$ & $\begin{array}{l}\text { AF, B, DF, } \\
\text { LN, N, M, S }\end{array}$ \\
\hline
\end{tabular}

No Estado de São Paulo, cerca de $80 \%$ das cultivares plantadas provém de tomateiros do grupo 'Santa Cruz', principalmente a cultivar Santa Clara, que predomina devido à resistência dos frutos ao manuseio, transporte e tradição de consumo. Assim, é importante ressaltar a suscetibilidade desta cultivar às diferentes estirpes de ToMV, na qual ocorrem sintomas mais severos do que os causados pelas estirpes de TMV descritas no Brasil.

Pelas propriedades físicas, o ToMV-SP apresentou PIT de $74^{\circ} \mathrm{C}$, PFD de $10^{-4}$ e LIV de 180 dias à temperatura ambiente, resultados que se mostraram semelhantes aos descritos para os tobamovirus (Brunt et al., 1996). Na preparação purificada, a concentração do vírus foi de $3,95 \mathrm{mg} / \mathrm{ml}$, e foram observadas partículas com cerca de $300 \mathrm{~nm}$ de comprimento em contrastação negativa, típicas de tobamovírus. O anti-soro produzido (ASToMV-SP) a partir desta preparação apresentou um título de 1:13.000 em ELISA-PTA.

O ToMV-SP reagiu com ToMV e TMV em ELISA-PTA e em imunomicroscopia eletrônica de transmissão, na qual observaram-se partículas rígidas fortemente decoradas com o AS-ToMV-SP (Figura 2) e AS-TMV-Pet. Mas, não reagiu com os anti-soros para as espécies FrMV e RGMV, confirmando os resultados obtidos nas plantas indicadoras.

Confrontando antígenos e anti-soros dos isolados ToMV-SP e TMV-Pet não foi possível diferenciar sorologicamente o ToMV de TMV, uma vez que os valores de absorbância da reação cruzada foram de 0,737 e 0,687 , respectivamente. Caner et al. (1990) e Duarte et al. (2002) já haviam verificado a necessidade de utilizar anticorpos monoclonais para diferenciar sorologicamente estas espécies.

Foram obtidos fragmentos de DNA com $850 \mathrm{pb}$ (Figura 1B), sequenciados (Figura 3) e comparados com outros depositados no GenBank. A similaridade de nucleotídeos e aminoácidos deduzidos variou entre 85 e $91 \%$ quando comparada com outras seqüências de ToMV, 75 e $83 \%$ com o TMV e 67 e $72 \%$ com o ORSV (Tabela 2). As comparações com outras espécies do gênero Tobamovirus apresentaram valores de similaridade inferiores a $65 \%$ confirmando a identidade do vírus como

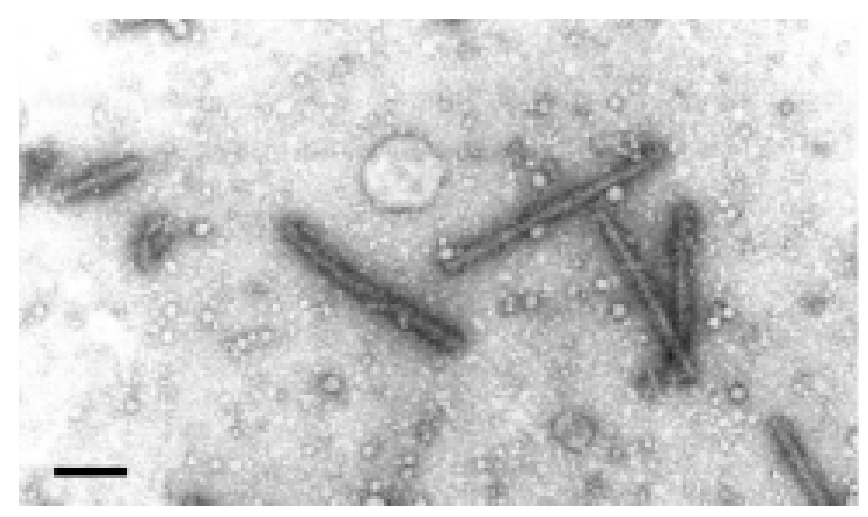

FIG. 2 - Micrografia eletrônica de imunomicroscopia de partículas típicas de tobamovírus de tomateiro (Lycopersicon esculentum) 'Santa Clara', proveniente de Guaratinguetá, utilizando o AS-ToMV-SP. A barra corresponde a $100 \mathrm{~nm}$. 


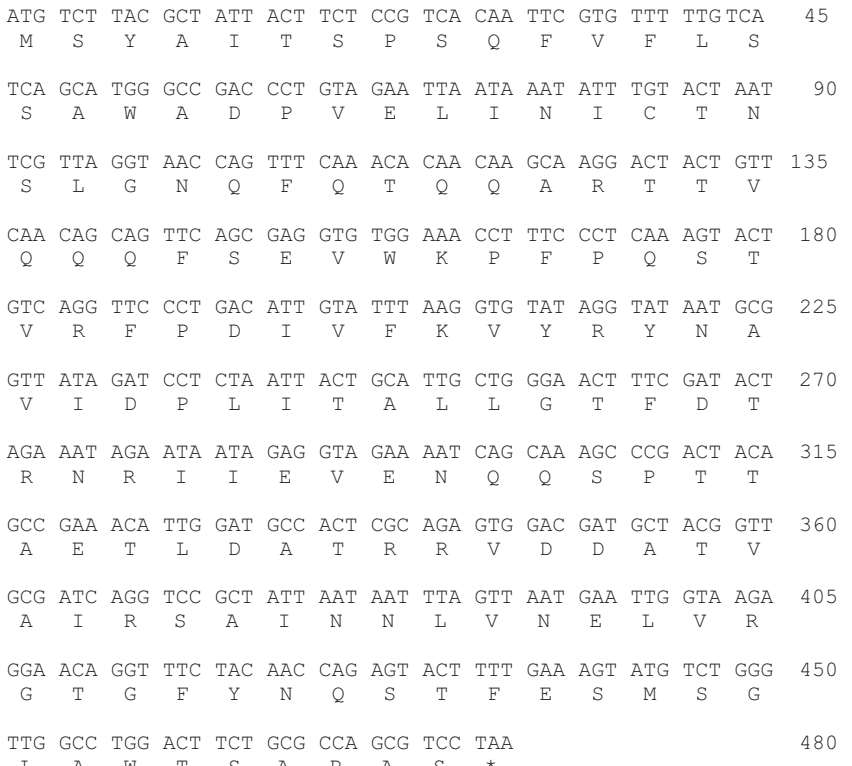

FIG. 3 - Sequiência de nucleotídeos (linha superior) e de aminoácidos deduzidos (linha inferior) do gene da capa protéica (CP) do Tomato mosaic virus isolado de tomateiro (Lycopersicon esculentum) 'Santa Clara' (ToMV-SP). Os nucleotídeos estão numerados a partir da extremidade 5 '. O asterisco $\left(^{*}\right)$ indica o códon de parada da ORF da CP; O número de acesso da sequiência no Genbank é AF411922.

TABELA 2 - Similaridade (\%) de nucleotídeos (abaixo da diagonal) e aminoácidos deduzidos (acima da diagonal) entre diferentes espécies e isolados de tobamovírus. As sequiências utilizadas nas comparações estão depositadas no GenBank

\begin{tabular}{|c|c|c|c|c|c|c|c|}
\hline Isolado* & $\sum_{0}^{0}$ & $\sum_{0}^{1}$ & $\sum_{0}^{T}$ & 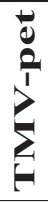 & $\sum_{i=1}^{1}$ & $\sum_{i=1}^{1}$ & $\begin{array}{l}\frac{1}{0} \\
\boldsymbol{\alpha}\end{array}$ \\
\hline ToMV-SP & - & 91 & 91 & 83 & 83 & 81 & 72 \\
\hline ToMV -I & 85 & - & 99 & 82 & 81 & 81 & 72 \\
\hline ToMV -1 & 85 & 99 & - & 81 & 81 & 81 & 72 \\
\hline TMV-pet & 76 & 74 & 74 & - & 97 & 95 & 70 \\
\hline TMV-L & 76 & 74 & 74 & 96 & - & 98 & 70 \\
\hline TMV-D & 75 & 73 & 73 & 95 & 98 & - & 68 \\
\hline ORSV & 67 & 66 & 66 & 63 & 63 & 62 & - \\
\hline
\end{tabular}

*ToMV-SP - isolado de tomateiro caracterizado neste trabalho (AF411922); ToMV-I isolado de Impatiens sp. (AY063743); ToMV-1 (AJ011934); TMV-pet - isolado de Petunia sp. (AY029262); TMV-L (X02144); TMV-D (X70884); ORSV (AF033848). *Entre parênteses estão os códigos de acesso no GenBank.

sendo o ToMV, estando estes valores de acordo com os obtidos por outros autores (Lartey et al., 1996).

No dendrograma, o ToMV-SP está isolado em um ramo, porém, compartilhando um mesmo ancestral com outros isolados de ToMV e TMV (Figura 4). Ohno et al. (1984) sugeriram que o TMV (estirpe comum e de tomate) provinha de um ancestral comum. Análises filogenéticas da ORF da capa protéica de espécies do gênero Tobamovirus indicam a proximidade entre

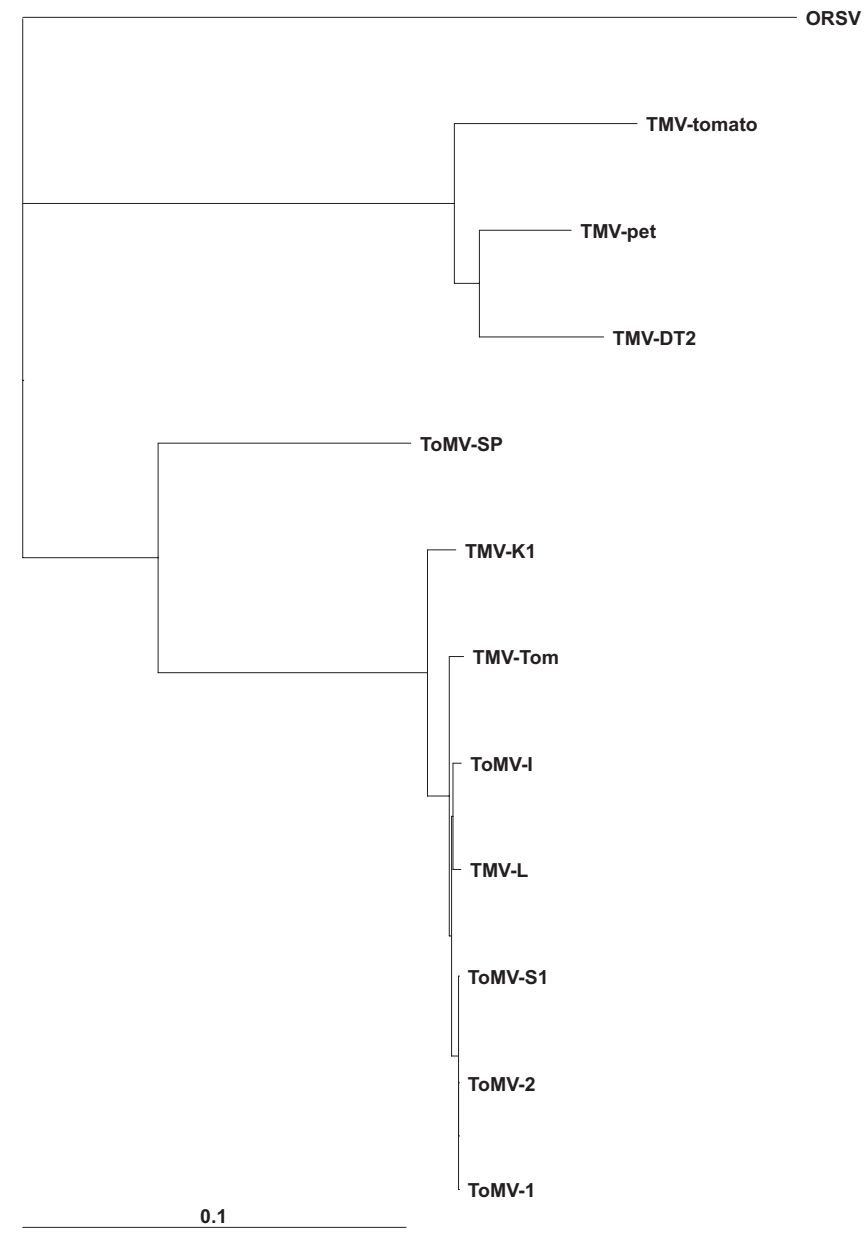

FIG. 4 - Dendrograma (Treeview 1.5) obtido por meio do alinhamento (Clustal X) de nucleotídeos de espécies de tobamovírus do subgrupo 1 depositados no GenBank: ORSV (AF033848); TMV-tomato (AF126505); TMV-Pet (AY029262); TMV-DT2 (X70884); ToMVSP (AF411922); TMV-K1 (AJ243571); TMV-tom (AF103779); ToMV-I (AY063743); TMV-L (X02144); ToMV-S1 (Z98201); ToMV-2 (AJ32845); ToMV-1 (AJ011934). A barra significa 0,1 substituições de nucleotídeos por sítio.

ToMV e TMV, o que dificulta a diferenciação destas pelo uso de anti-soros policlonais (Lartey et al., 1996). Gibbs (1999) também observou que as espécies do subgrupo 1 compartilham de um mesmo ancestral comum.

A correta identificação de vírus infetando tomateiros é importante pois esta é uma das hortaliças mais cultivadas no mundo. O Brasil está entre os nove maiores produtores (Duarte et al., 2002) e o estado de São Paulo é responsável por cerca de $33 \%$ da produção nacional (IEA, 2000). Para tanto, a demanda anual de sementes é de aproximadamente 80 ton. Deste total, cerca de $40 \%$ é importada, principalmente dos Estados Unidos (Nascimento et al., 1994), representando uma possível entrada de novas estirpes de tobamovírus, transmitidos por sementes. Colariccio et al. (2002), empregando sorologia, detectaram o ToMV-SP em sementes de linhagens homozigotas (Tm- $\left.2^{2}\right)$ experimentalmente infetadas.

Neste trabalho, observou-se que somente a linhagem 
com o alelo Tm-2, em homozigose, apresentou resistência ao ToMV-SP, sugerindo que os tomateiros em homozigose (Tm2/Tm-2) seriam os mais recomendados para o desenvolvimento de cultivares resistentes à essa estirpe. Estes dados fornecem subsídios para estratégias de controle e adequação dos programas de melhoramento genético, visto que os tobamovírus do subgrupo 1 têm sua provável origem nas Américas, em regiões da Bolívia, Brasil e Peru, havendo, portanto, uma maior pressão de inóculo, principalmente devido à existência de espécies de Nicotiana já descritas como originárias destas mesmas regiões e hospedeiras naturais destes tobamovírus (Gibbs, 1999).

\section{AGRADECIMENTOS}

Os autores agradecem aos Pesquisadores M.A.V. Alexandre (Instituto Biológico, São Paulo, Brasil), P. Roggero (Istituto di Virologia Vegatale, Torino, Itália) e D.E. Lesemann (Instituto de Biologia, Braunsehweig, Alemanha) pelos antisoros cedidos.

\section{REFERÊNCIAS BIBLIOGRÁFICAS}

ANTIGNUS, Y., WANG, Y., PEARLSMAN, M., LACHMAN, O., LAVI, N. \& GAL-ON, A. Biological and molecular characterization of a new cucurbit-infecting Tobamovirus. Phytopathology 91:565-571. 2001.

BASTOS, H.B., PAVAN, M.A. \& SILVA, N. Estirpes do vírus do mosaico do tomateiro presentes em regiões produtoras de tomate do Estado de São Paulo. Summa Phytopathologica 1:14-16. 1999.

BLANCARD, D. Enfermidades del tomate. Editora Mundi-Prensa, INRA, Paris, 1996.

BRUNT, A., CRABTREE, K., DALLWITZ, M.J., GIBBS, A.J. \& WATSON, L. Viruses of Plants:Descriptions and lists from the vide data base. CABI International, United Kingdom, 1996.

CANER, J., COLARICCIO, A., CHAGAS, C.M., ALBA, A.P.C. \& VICENTE, M. Identificação de um isolado do vírus do mosaico do tomateiro (ToMV) no Estado de São Paulo. Fitopatologia Brasileira 15:347-350. 1990.

COLARICCIO, A., ROGGERO, P., CHAVES, A.L.R. \& EIRAS, M. Lateral-flow:um teste rápido para detecção de fitovírus. Summa Phytopathologica 28:104. 2002 (Resumo).

COLARICCIO, A., EIRAS, M., CHAVES, A.L.R., ROGGERO, P. \& CHAGAS, C.M. Diversidade de tospovírus em olerícolas no Estado de São Paulo. Summa Phytopathologica 27:177-182. 2001.

COSTA, A.S., NAGAI, H. \& COSTA, C.L. Mancha parda interna do tomate associada à infecção pelo vírus do mosaico do fumo. Revista de Olericultura 11:77-78. 1971 (Resumo).

DUARTE, K.M.R., GOMES, L.H., ANDRINO, F.G., LEAL Jr., G.A., SILVA, F.H.B., PASCHOAL, J.A.R., GIACOMELLI, A.M.B. \& TAVARES, F.C.A. Identificação do vírus do mosaico do tomateiro (ToMV) Tobamovirus, por meio de anticorpos monoclonais. Scientia Agrícola 59:107-112. 2002.

EIRAS, M., CHAVES, A.L.R., COLARICCIO, A., HARAKAVA, R., ARAUJO, J. \& CHAGAS, C.M. Caracterização do Tomato chlorotic spot tospovirus isolado de jiló no Estado de São Paulo. Fitopatologia Brasileira 27:285-291. 2002.
FARIA, J.C., BEZERRA, I.C., ZERBINI, F.M., RIBEIRO, S.G. \& LIMA, M.F. Situação atual das geminiviroses no Brasil. Fitopatologia Brasileira 25: 125-137. 2000.

FERNANDES, J.J., CARVALHO, M.G. \& ALMEIDA, E.G. Distribuição do mosaico em tomatais de duas regiões produtoras de Minas Gerais. Fitopatologia Brasileira 8:625. 1983 (Resumo).

FLETCHER, J.T. \& MCNEILL, B.H. The identification of strains of tobacco mosaic virus from crops in Southern Ontario. Canadian Journal of Microbiology 17:123-128. 1971.

GIBBS, A. \& HARRISON, B.D. Plant virology. The principles. Edward Arnold Publication. London. 1976.

GIBBS, A. Evolution and origins of tobamoviruses. Philosophical Transactions of the Royal Society of London Series B 354:593-602. 1999.

HOLLINGS, M. \& HUTTINGA, H. Tomato mosaic virus. CMI/ AAB. Descriptions of plant viruses. $n^{\circ} .156,1976$.

Informações Estatísticas da Agricultura (Anuário IEA-1999), São Paulo, Instituto de Economia Agrícola, Governo do Estado de São Paulo, v.11, n.1, 2000, pp.233.

KOBORI, R.F., WIERZBICKI, R., DELLA VECCHIA, P.T., PAVAN, M.A. \& REZENDE, J.A.M. Ocorrência do Pepper mild mottle virus (PMMoV) em pimentão (Capsicum annuum) cultivado sob estufas no Estado de São Paulo. Fitopatologia Brasileira 26:516. 2001 (Resumo).

LARTEY, R.T., VOSS, T.C. \& MELCHER, U. Tobamovirus evolution:genes overlaps, recombination, and taxonomic implications. Molecular Biological Evolution 13:1327-1338. 1996.

MARITAN, A.C. \& GASPAR, J.O. Infecção de Zinnia elegans pelo Tobacco mosaic virus resultante da interação com um potyvírus. Fitopatologia Brasileira 26:533. 2001 (Resumo).

MOREIRA, S.R., COLARICCIO, A., CHAVES, A.L.R., EIRAS, M. \& GALLETI, S.R. Identificação de uma nova estirpe do vírus do mosaico do tomateiro através de hospedeiras diferenciais. Summa Phytopathologica 26:100. 2000 (Resumo).

MOREIRA, S.R., COLARICCIO, A., EIRAS, M. \& CHAVES, A.L.R. Caracterização molecular do Tomato mosaic virus isolado de tomateiro no Estado de São Paulo. Fitopatologia Brasileira 26:515. 2001 (Resumo).

NASCIMENTO, W.M., SILVA, J.B. \& PESSOA, H.B.S.V. Produção de sementes de tomate para a indústria em Brasília / DF. Horticultura Brasileira 12:196-198. 1994.

OHNO, T., AOYAGI, M., YAMANASHI, Y., SAITO, H., IKAWA, S. MESHI, T. \& OKADA, Y. Nucleotide sequence of the Tobacco mosaic virus (tomato strain) genome and comparison with the common strain genome. Journal of Biochemistry 96:1915-1923. 1984.

RIVAS, E.B., DUARTE, L.M.L., ALEXANDRE, M.A.V. \& CHAGAS, C.M. Viroses em orquideas no Estado de Sao Paulo. Arquivos do Instituto Biologico 63?31-35. 1996.

SAMBROOK, J., FRITSCH, E.F. \& MANIATIS, T. Molecular Cloning:A laboratory manual. $2^{\text {nd }}$ ed. New York, Cold Spring Harbor Laboratory Press. 1989.

VAN REGENMORTEL, M.H.V., FAUQUET, C.M., BISHOP, D.H.L., CARSTENS, E.B., ESTES, M.K., LEMON, S.M., MANILOFF, J., MAYO, M.A., McGEOCH, D.J., PRINGLE, C.R. $\&$ WICKNER, R.B. Virus Taxonomy Classification and Nomenclature of Viruses. Seventh Report of the International Committee on Taxonomy of Viruses. Academic Press, California, USA. 2000. 